\title{
A construção da identidade nacional moçambicana no pós- independência: sua complexidade e alguns problemas de pesquisa
}

Marçal de Menezes Paredes*

Resumo: O presente artigo aborda a complexidade da construção nacional em Moçambique, tendo especial atenção ao período pós-Independência (1975). Inicialmente discute algumas matrizes teóricas sobre o caso das identidades africanas de modo geral e dos nacionalismos africanos de modo particular. Argumenta pela necessidade de abdicar das leituras generalistas e propõe o enfoque do caso moçambicano. Analisa a construção do projeto político e ideológico da FRELIMO (Frente de Libertação de Moçambique) tendo atenção na forma como é compreendida a construção nacional em Moçambique. Destaca, assim, a maneira como as identidades tradicionais e as heranças do período colonial e racista são contrapostas ao projeto de criação de um Homem Novo no país, através de uma particular leitura da moçambicanidade.

Palavras-chave: História de Moçambique. Identidade nacional. Nação e nacionalismo. Socialismos africanos. Construção do Homem Novo.

\section{Introdução}

Neste artigo abordo a complexidade da construção da nação e da identidade nacional em Moçambique, tendo especial foco o contexto pós-independência (25 de junho 1975). Para isso, discutirei brevemente algumas matrizes políticas e historiográficas que se debruçaram sobre a questão identitária na África em geral, assim

* Doutor em História pela Universidade de Coimbra. Professor Adjunto, PUCRS. E-mail: marcal.paredes@pucrs.br. 
como debaterei o alcance de algumas referências teóricas sobre o "nacionalismo africano" em particular. Em seguida, recuperarei alguns dados importantes da história contemporânea de Moçambique, particularmente na transição da luta anticolonial, dando ênfase ao ideário de formação da FRELIMO (Frente de Libertação de Moçambique), até o período posterior à independência nacional, sobretudo no que tange às políticas levadas a cabo pelo governo Samora Moisés Machel, tendo como propósito a construção de nova identidade nacional em Moçambique. Por fim, e com base nesses fatores anteriormente referidos, apresentarei algumas reflexões sobre o fato de que, embora possa-se afirmar da consolidação da identidade nacional moçambicana como "comunidade de destino" (MACAMO, 1996), esta leitura não pode se coadunar como uma versão simples e unitária da moçambicanidade ${ }^{1}$ tendo que ser considerados vários elementos dinamizadores desta ${ }^{2}$.

A construção do nacionalismo moçambicano pode ser divida, pelo menos, em três períodos históricos: o primeiro momento (1910/20-1962), antes da eclosão da luta armada pela independência, em que o associativismo e o jornalismo tiveram um papel importante nas demandas sociais e na luta anticolonial (ZAMPARONI, 1998); um segundo momento, marcado pelo conflito armado e pela formação da FRELIMO, reunindo diversos movimentos, tendo como objetivo comum a libertação nacional frente ao salazarismo colonialista português (1962-1975); e um terceiro, iniciado imediatamente após a Independência, tendo como principal promotor o ideário da Frelimo (convertida de Frente nacionalista ampla em Partido único revolucionário, sendo esta a diferença entre a designação FRELIMO/ Frelimo), sob a liderança de Samora Machel (1975-1986)³.

Neste artigo, darei mais atenção apenas à última fase deste processo. Estarei preocupado com o âmbito da promoção e da construção de um projeto nacional que visou à homogeneização do cidadão moçambicano, conforme determinado projeto político. De maneira algo particular, o caso moçambicano diferencia-se da construção do nacionalismo pela via do "socialismo africano", tal como proposto, entre outros, por Julius Nyerere, na Tanzânia (cuja preocupação com a adaptação do marxismo-leninismo às condições do continente é patente). 
É consensual estabelecer a centralidade da FRELIMO na organização, promoção e proclamação da independência nacional de Moçambique. Formada em 1962, na Tanzânia, através da agregação de três movimentos de luta anticolonial já existentes - a UNAMO (União Africana de Moçambique), a MANU (Mozambique African Nation Union) e a UDENAMO (União Democrática Nacional de Moçambique) (ENDERS, 1997) - esta grande Frente de Libertação tinha um caráter nacionalista amplo e contava com apoio internacional dos seus vizinhos ao norte do país (Malaui, Zâmbia, Rodésia do Sul/ Zimbábue e Tanzânia). Seu ideário era marcado por um forte antissalazarismo, sendo sua proximidade com o Bloco Soviético ainda de caráter estratégico no âmbito do anticolonialismo (VIEIRA, 2011). Fato é, contudo, que a FRELIMO, enquanto frente política ampla, e sob a liderança de Eduardo Mondlane, não se teria proclamado marxista-leninista durante a luta pela independência de Moçambique (MALOA, 2011). Este postulado será, contudo, modificado no imediato contexto pós-Independência, já vinculado a políticas de construção nacional identitária.

\section{As identidades e a identidade nacional na África}

A temática da construção das nações, dos nacionalismos e da identidade nacional, como se sabe, é bastante corrente, tendo sido reaceso o debate nos últimos vinte ou trinta anos. Querelas acadêmicas entre teses primordialistas e modernistas, etnossimbolistas e construtivistas, pós-colonialistas ou seus críticos, fazem parte da história do campo acadêmico ${ }^{4}$. Contudo, quando olha-se para o caso da construção das nações na África, tem-se a sensação de um enorme desequilíbrio: primeiro, porque o número de textos disponíveis sobre o tema é bastante reduzido; segundo, porque a maioria dos autores geralmente trabalha o tema das identidades nacionais ou num viés claramente político ou sob uma visão francamente generalista; e terceiro, o grau destes fatores anteriormente apontados fica ainda mais exacerbado quando se pesquisa a história dos países africanos com língua oficial portuguesa (ainda que recentemente tenha-se publicado bons e interessantes trabalhos). $\mathrm{O}$ resultado disso tudo

Anos 90, Porto Alegre, v. 21, n. 40, p. 131-161, dez. 2014 
está fácil de perceber: ressoam ainda no imaginário (acadêmico inclusive) as marcas dos discursos estereotipados sobre um objeto homogêneo chamado África, estando muitas vezes atreladas a este construto as noções de tribo ou sociedades simples. Quase sempre há uma (implícita) racialização dos discursos tendo um viés essencialista sobre a identidade social. Quase nunca estes temas são tratados na sua historicidade, estabelecendo fronteiras conceituais híbridas e mostrando a questão identitária como um discurso político, como construtor de memórias históricas, como um campo aberto e, por isso mesmo, necessariamente propício a resignificações em diferentes contextos intelectuais. Em resumo: infelizmente, quando pensa(m)-se a(s) identidade(s) africana(s) (tradicionais ou modernas), ainda ecoam ou os ditames hegelianos sobre a sua falta de história ou os inúmeros estereótipos típicos da antropologia evolucionista e tão fortemente presentes nos relatos dos viajantes/aventureiros europeus dos finais do século XIX e início do século XX. A manutenção do jogo binário de compreensões tais como civilização/barbárie, luz/ trevas, modernidade/tradição, progresso/atraso, sobretudo quando busca-se compreender o vasto e diverso continente africano, acaba, na maioria das vezes, reforçando os postulados do colonialismo cultural.

A construção das identidades africanas esteve sempre no horizonte cultural extra-africano. De modo geral, pode-se dizer que a África como unidade e como objeto analítico foi um construto europeu forjado no século XVIII-XIX (MUNDIMBE, 2013). Inicialmente, pela narrativa dos viajante-exploradores (Livingstone, Stanley, Serpa Pinto, Capelo e Ivens, entre outros), logo foram transformadas em subsídios factuais e descritivos para a elaboração de teorias (pseudo)científicas no século XIX. Conforme Paul Gilroy (2008), as identidades africanas foram sendo elaboradas como contracultura da modernidade. Como se sabe, este processo - político e epistêmico - está marcado fortemente pela querela colonialista-anticolonialista em todas as suas variadas esferas (educação, economia, política etc.). Suas decorrências traduziram-se também em matrizes historiográficas de ampla força no imaginário ocidental.

O historiador congolês Elikia M'Bokolo aponta duas matrizes de leitura da história da África. A de viés colonialista, de modo geral, é responsável pela sedimentação de muitos estereótipos sobre a 
África, todos, quase sempre, reforçando a ideia de uma "África negra" escalonada à maneira evolucionista na idade das trevas, organizada em tribos e crivada por guerras, pela fome e por doenças endêmicas que ressoavam a marca de uma terra selvagem e à qual o "fardo do homem branco" caberia elevar. No contexto pós-II Guerra Mundial, erige-se outra matriz historiográfica de leitura do passado africano - a matriz "nacionalista". Trata-se de um contra-argumento político às teses colonialistas que afirma a positividade e a unidade essencial da “civilização negra". Muito forte na segunda metade do século XX, este viés analítico pretende marcar positivamente o caráter civilizacional africano. Tratava-se de instaurar uma ruptura política contra as teses da inferioridade africana tão difundidas pelo colonialismo. Inspirados, de maneira geral, pelo pan-africanismo, do americano W. E. B. Du Bois (entre outros), pelos escritos vinculados ao grupo da Négritude, do senegalês Léopold Sédar Senghor e do martinicano Aimé Césaire, mas também pelas teses de outro intelectual senegalês, Cheik Anta-Diop, esta matriz - que contém significativas diferenças internas, vale grifar - deu um importante contributo ao denunciar o preconceito racial contido nas teses ditas "científicas" do século XIX. Mais do que isso, sua dispersão como modelo de leitura cultural do "africano" esteve ligada, em maior ou menor grau, aos movimentos de independência e liberdade política no continente.

Contudo, de maneira geral, e por mais opostas que tenham sido suas opções políticas, ambas as visões sobre a África - das teses colonialistas eurocêntricas às teses nacionalistas e afrocêntricas - tocam-se num ponto nevrálgico: a mobilização da noção racial. Negativa e inferior para uns, positiva e afirmativa para outros, o fato é que muito do que já se escreveu sobre a "África" ainda segue preso a este movimento pendular que vai da direita à esquerda e do negativo ao positivo racializado. Diante destes binarismos, M’Bokolo assevera que devemos "renunciar às interpretações maniqueístas". Há, de fato, que renunciar às simplificações e dar margem para pensar as complexidades sociais existentes em cada contexto específico (com atenção ao dinamismo das fronteiras móveis e das margens flexíveis) sem deixar de constatar as violências dos colonialismos distintos que puseram em contato diferentes potências europeias e múltiplas sociedades africanas. Esse contato, segundo o autor, gerou

Anos 90, Porto Alegre, v. 21, n. 40, p. 131-161, dez. 2014 
A construção da identidade nacional moçambicana...

"violências, catástrofes e transformações abruptas", sua dispersão, entretanto, teria variado

[...] em função de lugares, do estado das sociedades, das suas capacidades e das suas estratégias de resistência, e que tais perturbações, inseridas como estavam em dinamismos de longa duração, suscitavam processos duradouros de reajustamento, de cooperação e de recusa, e geravam frequentemente relações de força e hierarquias inéditas entre regiões e os grupos sociais antigos e novos (MBOKOLO, 2011, p. 330).

Creio que o caso moçambicano em tela neste texto apresentará alguns elementos para repensar os esquemas generalizantes costumeiramente aceitos.

Este debate no âmbito das historiografias (e seus projetos políticos) construiu marcas de discurso identitário assim como recuperou (a seus distintos modos) "trajetos" histórico-evolutivos do "africano". Estes postulados também acabaram por impregnar o campo acadêmico que se voltava à análise da "construção da nação" no continente africano. Pode-se observar um interesse crescente no "caso africano" desde a primeira geração de especialistas ${ }^{5}$ que, nas universidades europeias e norte-americanas especialmente, pretendiam explicar as "novas nações" na África no período do posterior a Segunda Guerra Mundial. A violência política, a xenofobia, os massacres e extermínios acontecidos durante as guerras mundiais (com importantes combates no continente africano, vale lembrar) marcaram o "nascimento" do campo acadêmico que se debruçou sobre o nacionalismo criticamente. E é justo neste contexto que eclode a onda de independências e a forte pressão internacional pela descolonização na África. Lembre-se, apenas a título de exemplo, a força política dos discursos de Kwame Nkrumah e do simbolismo da Independência da ex-colônia britânica conhecida por Gold Coast, em 1957, logo depois redefinida e nomeada como o Estado-Nacional Independente de Gana. Dessa feita, conforme alguns críticos, os "novos" nacionalismos africanos teriam a marca de uma "doença política" europeia - o nacionalismo - responsável pelas atrocidades acontecidas entre 1939 e 1945.

Anos 90, Porto Alegre, v. 21, n. 40, p. 131-161, dez. 2014 
Autores como Hans Kohn, Wallace Sokolsky, Carlton Heyes, Elie Kedourie, entre outros, embora sempre tenham estado mais voltados a analisar criticamente os nacionalismos europeus, não deixaram jamais de pôr os olhos no processo político que se desenrolava na África. Suas análises sobre "os nacionalismos africanos" têm um ponto em comum: apontam para o transporte teórico-político da matriz europeia. Seus argumentos podem ser resumidos - com alguma simplificação, naturalmente, - do seguinte modo: após o forte contributo dos batalhões africanos nos dois grandes conflitos mundiais, um lastro assimilacionista teria dado o tom do regresso dos combatentes às suas terras. A demanda por mais liberdade e por maior autonomia política - afinal os africanos teriam defendido a "liberdade" nos exércitos francês e inglês, por exemplo - teria sido um elemento importante na construção por soberania nacional. O exemplo deletério dos nacionalismos étnicos e xenófobos na Europa, ou mesmo o potencial repressor do Estado na construção das nações-cívicas do velho continente, estaria sendo requentado como matriz para a elaboração dos discursos nacionalistas na África. De maneira geral, o "modernismo" nacionalista acaba sendo quase sempre um eco da matriz política centro-europeia.

Outros autores apostaram no justo polo oposto da discussão. E se na Europa sempre houve defensores da credibilidade étnica e do recurso à história medieval como "raízes" culturais importantes, não tardou a aparecerem olhares sobre a África com estas lentes. Autores como Adrian Hastings, por exemplo, não hesitaram em afirmar a credibilidade do conceito de etnia através de um acento essencialista. Neste quadrante, os ecos de "tribalismo" podem ser positivos: apelariam certamente para um passado remoto de reinos, reis e rainhas africanos como recurso mítico-simbólico para a construção de matrizes étnico-identitárias. Terece Ranger, por sua vez, estabelece um forte contra-argumento aos "etnicistas" ao afirmar que teria sido no âmbito das políticas colonialistas britânicas que o associativismo étnico africano teria sido induzido nas ex-colônias inglesas. Sensos demográficos, clubes de dança, prática de esportes e muitas outras esferas de associação teriam agido no sentido de fomentar o reconhecimento étnico por parte das populações africanas, tendo objetivo de replicar, no melhor dos casos, o parâmetro 
multiétnico liberal da commonwealth. Em ambos os casos, contudo, ressoariam ainda os debates no âmbito da anglofonia europeia sobre a existência das nações antes ou depois de 1780, sobre a legitimidade monárquica multinacional (chocando-se com os nacionalismos irlandês e escocês, por exemplo), assim como a credibilidade ou não dos processos de luta política e referência historiográfica ao passado medieval naquele contexto intelectual ${ }^{6}$.

Ainda outra vertente analítica apontaria um caminho explicativo diverso, quase a meio-termo entre o modernismo e o primordialismo. Tome-se como exemplo o texto de Olatunji Oloruntimehin, presente no volume VIII da monumenal História Geral de África, organizada por Joseph Ki-Zerbo e editada pela UNESCO, em 1993. De modo geral, a explicação para o fortalecimento do nacionalismo africano em parte replicam a importância da matriz cultural europeia no movimento nacionalista africano - especialmente na atividade da imprensa e dos sindicatos - mas agrega-lhe dois outros contributos importantes: uma visão abrangente ao desenvolvimento do capitalismo imperialista europeu em suas garras sobre o continente africano e o recurso, mesmo nos setores mais "ocidentalizados", a uma progressiva tomada de consciência social sobre o que foi chamado de "africanidade essencial" (OLURUNTIMEHIN, 1993, p. 671). Não custa lembrar o caráter conceitual e político desta interpretação, assinalando haver outras tentativas de reflexão sobre a África para além da sua visão racializada (APPIAH, 2008).

Mesmo que esta exposição tenha sido ligeira e, por ventura, ter cometido eventuais simplificações, parece claro que em todos os caminhos costumeiramente trilhados para pensar a problemática da identidade nacional no extenso continente africano, acabaram por reduzir o objeto em causa - a construção da nação e a identidade nacional - a mera parte de um grande panorama geral. Chamem-se as opções de europeístas ou africanistas, neocolonialistas ou nacionalistas, parece ser inconteste um lugar de análise distanciado e facilitador de grandes esquemas histórico-sociais. A África - como constructo político-intelectual unitário e homogêneo - segue sendo um postulado epistêmico resiliente. 
Mais recentemente novas perspectivas de análise deram outros rumos ao debate. Patrick Chabal, por exemplo, nega a relação causal direta entre a modernidade e a construção do nacionalismo africano. Ao contrário deste postulado modernista - em que concordam diferentes autores como Eric Hobsbawm, Hans Kohn ou Elie Kedourie, entre outros -, a perspectiva de Chabal (2010) afirma praticamente o oposto. Tendo em vista o caso africano, a relação é inversa à europeia: o nacionalismo na África é considerado como o promotor da modernização das sociedades (e não seu resultado, como no caso europeu). Esta consideração é da mais alta valência, na medida em que descortina o caráter de promoção de novos parâmetros de organização social inseridos no contexto pós-independência. Assim, as "novas" nações africanas teriam mais um apelo ao futuro a ser construído do que um passado a ser preservado. ${ }^{7} \mathrm{E}$ neste patamar que se começa a perceber a importância de tratar cada caso do "nacionalismo africano" em sua especificidade.

\section{Do costume à moçambicanidade}

É correto afirmar a existência de múltiplas identidades étnicas existentes no espaço que durante o período colonial português foi sendo chamado de Moçambique. Contudo, a vinculação de grupos étnico-culturais do período pré-colonial com o espaço político-territorial pós-colonial parece ser um trajeto com muitas fragilidades, além de escamotear certa mobilização romântica e historicista do tempo histórico.

Conforme Malyn Newitt,

In the immediate precolonial period dating from the middle of nineteenth century the country was dominated by three powerful and expanding cultural and political systems: the Islamic expansion north of the Zambezi carried by the Yao and the coastal Swahili and underpinned by the slave trade; the movement of the Afro-Portuguese out of the Zambezi 
valley in search of slaves, ivory and land; and the conquest of much of the area south of the Zambesi by the Gaza state bringing with it an overlay of Nguni military, cattle-owning culture. Althoug these established a kinf of a culture hegemony that appeared to divide the country roughly into three zones, there were always underlying survivals of past regimes and older cultures witch made Mozambique a palimpsest, resisting simple description (NEWITT, 2002, p. 187).

Merece alguma reflexão a designação de "palimpsesto" cultural para Moçambique. Como se sabe, um palimpsesto significa etimologicamente o "riscar de novo". Sua utilização para a formação cultural moçambicana remete ao caráter de reescrita, ressignificação e, sobretudo, para a existência de múltiplas camadas de significado ou de "presenças/ausências" culturais. Simboliza, resumindo, a impossibilidade de recuperação total de uma postulada essência original. Vale grifar, em adendo ao próprio excerto de Newitt anteriormente citado, a existência de presenças importantes de comunidades de gregos, turcos, indianos e chineses ao longo do século $\mathrm{XX}^{8}$.

A aceitação da existência de múltiplas camadas culturais ao longo do tempo no território nacional moçambicano não retira, contudo, a necessidade de pesquisas sobre algumas marcas culturais do passado. Algumas fontes são recheadas de informações nesse sentido. Destaco duas: Os Usos e Costumes dos Bantos, escrita pelo missionário presbiteriano suíço Henri Junot, publicada em 1913, e O Folclore Moçambicano e as suas tendências, cuja autoria é do importante intelectual moçambicano José Craveirinha. A obra de Junot reflete suas inúmeras vivências pelo interior das terras, desde a década de 1890, período das “campanhas de ocupação" do colonialismo português, experiência que o levou a ser expulso pelas autoridades coloniais, por seu "excesso" de cumplicidade com as populações locais. A obra teve sua primeira edição em inglês em 1912/13, tendo sido traduzida para o português em 1917 (FELICIANO, 1996, p. 17). A segunda referência é o livro de José Craveirinha, O Folclore Moçambicano e as suas tendências, formado por textos publicados pelo autor no jornal O Brado Africano, entre os anos 1952 e 1987. Craveirinha é um autor muito conhecido por sua obra literária, tendo sido vencedor do Prémio Camões em 1991. Os textos que formam a edição do livro 
mencionado dão mostras de um Craveirinha folclorista, escrevendo muitas vezes com pseudônimo ${ }^{9}$, refletindo já o período do nacionalismo moçambicano nas páginas da imprensa local.

As diferenças contextuais e cronológicas entre as obras são relevantes. Mais importante parece-me, entretanto, a diferença do escopo analítico adotado: embora a primeira fala de "usos e costumes" dos Bantos, a verdadeira análise recai sobre os Tsongas, grupo étnico ao qual o autor reputa inexistir "unidade nacional" (JUNOT, 1987, p. 34). A segunda obra referida, por sua vez, aborda a existência do "folclore" já no âmbito de uma "moçambicanidade" que merece ser recuperada e enaltecida, tratando de temas como a mestiçagem, a difusão cultural, a música popular moçambicana. São sintomáticas as considerações do autor quando advoga pelo caráter nacional da marrabenta e sua vinculação aos "mestiços e negros de convívio desruralizado" (CRAVEIRINHA, 2009, p. 52). Como bom folclorista, Craveirinha explica o processo de mistura já marcado pelo nome da dança: rebenta, do português acrescido do prefixo ma da língua Ronga. A forma linguística da marrabenta já simbolizaria a mestiçagem moçambicana transmutada em dança e patrimônio nacional.

A análise de uma declaração da FRELIMO de 1967, a propósito de uma crise política interna, permite perceber como era compreendida a questão nacional e étnica pelos membros da luta anticolonial em Moçambique. O texto oficial é assinado por Eduardo Mondlane e afirma "[...] que a realidade étnica moçambicana não é nítida e simples". Mesmo assim, há uma tentativa de conceituação da "tribo" através da adoção da "língua comum", dos "usos e costumes" e da "organização militar e económica". Diante desta definição, estes seriam os "diferentes grupos étnicos ou tribais": NYANJA (ocupando as margens do lago Niassa), MACUA (ocupando as províncias de Moçambique, parte da Zambézia, Niassa e Cabo Delgado), YAU (ocupando a maior parte do Niassa), MACONDE (na província de Cabo Delgado), SENA (na Zambézia, Manica e Sofala), NDAUNYAI-SHONA (Manica e Sofala), TSONGA-VATSUA-RONGA (maior parte da província de Gaza, Inhambane e Lourenço Marques).

Logo percebe-se, por um lado, casos de superposição ou convivência de diferentes "tribos" em uma mesma região, e, por outro lado, algumas divisões bem nítidas entre as províncias do norte e do 
sul (Gaza, Inhambane e a capital Lourenço Marques). Em seguida, o documento afirma o primado da unidade nacional através do recurso ao mesmo tronco linguístico encontrado nos diferentes grupos: "[...] apesar de haver variações de conduta entre um grupo e outro, os usos e costumes do nosso povo são semelhantes. Em primeiro lugar, nós pertencemos à nossa família linguística Banto, caracterizada pela mesma forma gramatical, mesma origem das palavras, mesma estrutura de frases e períodos". Em seguida, afirma-se que "[...] o convívio entre indivíduos de tribos diferentes e a incorporação forçada de grupos étnicos conquistados durante as guerras intertribais, resultaram numa mescla e interposição de usos e costumes das várias populações de Moçambique". (MONDLANE, 1967 apud MUIUANE, 2009, p. 81-82). Por fim, denuncia-se que a facilidade com que os portugueses teriam conquistado Moçambique teria sido "em grande parte o resultado das divisões tribais e étnicas do nosso povo". Os portugueses teriam usado a regra do "dividir para dominar", numa "tática tipicamente imperialista". Ao fim do documento, considera-se que "faltava-nos ainda a consciência nacional". O documento assinado por Eduardo Mondlane, então presidente da FRELIMO, afirma que esta

[...] encontra-se empenhada na missão sagrada de unir as massas populares contra o invasor comum" [difundido] “energias até então dispersas [para] transformá-las em energias nacionais, numa só realidade, numa só força bélica. A FRELIMO está criando uma nação que se vai libertando do jugo português. A Luta de Libertação Nacional é em si própria um processo de criação de uma nova realidade [...] Não há antagonismo entre as realidades da existência de vários grupos étnicos e a Unidade Nacional. Nós lutamos juntos, e juntos construímos e recriamos o nosso país, produzindo uma nova realidade - um Novo Moçambique, Unido e Livre (MONDLANE, 1967 apud MUIUANE, 2009, p. 87-88).

A Declaração do II Congresso da FRELIMO, em julho de 1968, apregoa o primado da unidade nacional. No seu Programa, afirmava a importância de "[...] eliminar todas as causas da divisão entre os 
diferentes grupos moçambicanos; construir a Nação Moçambicana, na base da igualdade de todos os moçambicanos e do respeito pelas particularidades regionais" (MONDLANE, 1967 apud MUIUANE, 2009, p. 114).

Após o assassinato de Mondlane, em 1969, algumas mudanças ocorreram no perfil da FRELIMO. A mais significativa destas alterações teria sido a luta interna pelo poder no âmbito dos seus quadros, querela que teria levado à expulsão de Uria Simango (um de seus fundadores). É neste contexto que a FRELIMO passa a ser liderada por Samora Machel, em 1970. As negociações da transição política para a Independência pós-Revolução dos Cravos em Portugal (já sob os auspícios do MFA português - Movimento das Forças Armadas), os termos do acordo de Lusaka, na Zâmbia, em 1974, entre muitos outros momentos-chave na história de Moçambique, deram-se já sob sua liderança.

Não se trata, aqui, de aproveitar uma potencial abertura às denúncias de crimes de guerra cometidos de parte a parte durante a luta anticolonial (como o Massacre de Mueda ou a Operação Nó Górdio, ambos levados a cabo pelo exército português), bem como no decorrer da guerra civil destravada após a independência entre Frelimo e RENAMO (Resistência Nacional Moçambicana) ${ }^{10}$. Mesmo havendo algum desequilíbrio sobre as denúncias a cada um dos polos envolvidos, importa salientar que aparecem patentes as admissões de exageros nas ações de repressão e violência generalizada a ponto de John Saul, um dos apoiadores intelectuais do Estado-Frelimo considerar que "[...] the sad trajectory os the Mozambican revolution has been devastating" (SAUL, 1993, p. 139) ${ }^{11}$.

\section{A luta contra o passado colonial "do Rovuma ao Maputo"}

Como presidente da I República em Moçambique ${ }^{12}$, Samora Machel, juntamente com a elite da Frelimo (partido único), foi o responsável pela reestruturação do projeto nacional. É neste ponto que sua governação põe em marcha um projeto de reenquadramento identitário. A lógica de uma ruptura radical com o passado - marcado 
pelo colonialismo português, pela exploração econômica burguesa, pelo racismo e pela cultura europeia assimilacionista - já antes difundida como o objetivo principal a ser alcançado, entrará em fase de construção de "nova" realidade. Eis aqui o ponto de interesse central no âmbito da discussão sobre as identidades africanas em geral e sob a construção das nações e dos nacionalismos na África. Após a Independência, foi adotado o modelo de partido único no país, opção justificada a partir de uma postulada coincidência entre o projeto da FRELIMO como representante das aspirações do "povo moçambicano do Rovuma ao Maputo" ${ }^{13}$.

Contudo, há um elemento clássico nas discussões sobre a formação das nações e das identidades: como foram formados os novos moçambicanos ${ }^{14}$ ? Este questionamento, que parte de uma matriz modernista do entendimento das construções nacionais, entretanto, não se coaduna de todo com esta referência teórica. Como já foi discutido anteriormente neste trabalho, não creio numa direta aplicação do padrão europeu de identidades nacionais nem tampouco na sua simples transferência às elites políticas africanas. Da mesma forma, é impreciso demais tratar do "caso africano" em geral. A análise do projeto nacionalista em Moçambique deixa clara a valência desta consideração.

Conforme vários autores (NEWIT'T, 2002; VIEIRA, 2011; MALOA, 2011), a FRELIMO desenvolveu sua formação política na experiência do exílio durante o contexto da luta anticolonial. Neste ponto, uma série de influências são quase sempre elencadas, havendo, contudo, divergências em relação às proximidades ideológicas. Para Guy Martin, o projeto de Samora Machel é bastante similar às propostas de Amílcar Cabral (2012, p. 80). Para outros autores, como Maloa (2011), a grande influência do primeiro presidente moçambicano seria a experiência do projeto tradicionalista da Ujamaa, de Julius Nyerere, na Tanzania. Neste ponto, há todo um construto que apela para o simbolismo do acampamento de formação ideológica da FRELIMO na Tanzânia (Nashingwea). Contudo, diferentemente de Cabral (que propunha a reafricanização dos espíritos, sendo sua proposta fortemente relacionada com as condições específicas da Guiné-Bissau) e mesmo diferentemente de Nyerere (que advogava certo socialismo tradicionalista africano, sendo crítico à adoção 
dogmática do padrão soviético), Samora Machel desenvolverá, junto com a FRELIMO, ao menos depois de 1969, um projeto que se propunha independente.

É isto o que se percebe quando temos atenção ao depoimento de Sérgio Vieira, membro fundador da FRELIMO e responsável por várias pastas e cargos importantes antes e durante a transição política, assim como após a proclamação da Independência. As palavras do antigo Diretor do Gabinete do Presidente da República entre 1975 e 1977 são bastante relevantes sobre a singularidade da construção socialista em Moçambique e da forma como eram percebidos os recursos étnicos ou tradicionais no âmbito da construção política moçambicana: "[...] mesmo entre países socialistas europeus havia reticências sobre a recusa da FRELIMO em explorar o caráter étnico da luta. As leituras da Tese sobre as Nacionalidades, de Estaline, tendiam a aplicar-se de um modo mecânico, dogmático e abusivamente generalizado a situações bem diferentes" (2013, p. 287). Trata-se, em parte, de um eco das críticas de Nyerere ao socialismo dogmático, principalmente opondo ao caráter de luta e de adoção da violência (o que Cabral e Fanon, por exemplo, propunham e que Nyerere recusava). Contudo, Machel e a FRELIMO irão também se afastar de uma aplicação direta do ideário de Nyerere, justamente no que tange ao processo de construção nacional. A recusa a qualquer vínculo étnico ou tribal marca este distanciamento. Ainda segundo Sérgio Vieira, para a FRELIMO, “[...] o racismo, o tribalismo ou o regionalismo, como dizia Samora combatiam-se com as mesmas armas que o colonialismo. Matar a tribo para faz̧er nascer a Nação também constituía, e constitui, um princípio director da revolução moçambicana". (VIEIRA, 2011, p. 285) Este desígnio político teria vindo de uma tácita consideração sobre a formação étnica dos povos moçambicanos e, sobretudo, pela interpretação crítica à forma como o colonialismo português teria se aproveitado das diversidades culturais na estratégia de "dividir para dominar". Pelo menos é isto o que argumenta Sérgio Vieira: “[...] o passado trouxera-nos a lição da experiência amarga da divisão, a derrota do país dividido por um punhado de conquistadores unidos e que sabiam explorar as fissuras entre nós, levando-nos a combater entre os moçambicanos em favor dos novos senhores (VIEIRA, 2011, p. 285). 
$\mathrm{Na}$ argumentação de Vieira, a adoção de nacionalismos africanos através da mobilização de fidelidades étnicas ou mesmo a partir de um postulado pan-afircanista racializado era, antes de tudo, um equívoco histórico e um neocolonialismo ideológico.

Os primado da raça, etnia, cor da pele, religião sobre o todo nacional constituiu uma visão e estratégia pouco científica, mas certamente enraizada na percepção primária e espontânea de um grande número. Visão e estratégia errada porque a realidade africana, a história do continente, também se podem analisar em termos das migrações, invasões, e expansionismos inter-africanos (VIEIRA, 2011, p. 287).

É curioso perceber que sua leitura da África aponta no mesmo sentido daquela proposta por Malyn Newitt. A diferença reside na consideração de que o palimpsesto identitário moçambicano (conforme Newitt) teria propiciado o uso político de cooptação de régulos e demais autoridades tradicionais no sentido de aproveitar as diferenças interafricanas como estratégia de desenvolvimento do colonialismo português. Possivelmente residam nesta consideração as diferenças entre Nyerere e Machel. Afinal, no caso do líder moçambicano, o passado não deveria ser recuperado (como propunha o líder tanzaniano), sendo necessária a construção de um "homem novo" em Moçambique. E o "novo" moçambicano teria de surgir na luta justamente contra este passado, tanto o tradicional como o colonial.

Em seu Discurso na tomada de posse como Presidente da República Popular de Moçambique, o Presidente da FRELIMO Samora Moisés Machel afirmava que a luta de libertação nacional de Moçambique teria sido contra o caráter imperialista do colonialismo português. De maneira clara e contundente, afirmava que "[...] o racismo, o regionalismo e o tribalismo como inimigos que deveriam ser combatidos ao mesmo título que o colonialismo" (MACHEL, 1975 apud MUIUANE, 2009, p. 478). Este posicionamento de Samora Machel marca a singularidade das decisões tomadas em Moçambique no que tange ao relacionamento entre identidades étnicas pré-coloniais, migrações e valores coloniais e o projeto de

Anos 90, Porto Alegre, v. 21, n. 40, p. 131-161, dez. 2014 
construção da identidade moderna moçambicana. Este caráter de singularidade moçambicana diante dos demais "nacionalismos" africanos ou mesmo dentro da via do "socialismo africano" é confirmado pela descrição de Sérgio Vieira, quando afirma ter sido “" [... esta atitude de definição da nacionalidade, do patriotismo e militância em função da cor da pele, região, etnicidade e até religião mostrava-se generalizada em numerosos países e esmo entre dirigentes de países africanos" (VIEIRA, 2011, p. 286). Samora Machel, no referido discurso de tomada de posse como Presidente da República Popular de Moçambique, ainda fala da necessidade de combater todas as "tendências divisionistas", sendo que "[...] na sociedade que queremos construir [...]”, diz Machel, "[...] o Estado assenta no princípio que todas as transformações no seio da sociedade são o resultado da luta do homem nas frentes de combate de classe, de combate pela produção e inovação científica assim como da contradição dos fenômenos da natureza”. Na conclusão de seu discurso (que contém muitos elementos importantes não tratados aqui), o presidente Machel reafirma que "[...] nossa luta nunca assumiu um caráter racial porque o nosso povo sempre soube distinguir o regime colonial-fascista do povo português" (MACHEL, 1975 apud MUIUANE, 2009, p. 490).

Sérgio Vieira revela ainda outra pista sobre construção do aparato intelectual e político de Samora Machel. Afirma que "[...] o encontro de Samora com o pensamento de Marx não resultava de uma leitura prévia [...]" e que o líder nacionalista teria conseguido elaborar uma síntese pessoal através de uma "[...] reflexão sobre a prática de várias décadas da sua vida pessoal, combinada com a análise dos grandes mestres", encontrando no que leitura teórica a "sistematização científica do vivido". Sobre Machel, Vieira afirma que

Com frequência citava e pedia que se estudasse a pequena brochura De Onde Vêm as Ideias Correctas de Mao Tsé Tung que desenhava uma aproximação à teoria a partir da práxis. Nesta reflexão de algum modo se explicam os conceitos que a FRELIMO desenvolveu ao longo do tempo, desde a noção de guerra popular prolongada, até ao poder popular e finalmente às teses do III Congresso (VIEIRA, 2011, p. 221). 
Parece nítido o caráter misto e independente presente na formação do ideário socialista moçambicano de Samora Machel. Por um lado, a reflexão teórica marxista teria contribuído para a associação do colonialismo e do racismo português ao imperialismo capitalista burguês. Contudo, ao que parece, houve sempre uma preocupação de colocar em relevo as peculiaridades do processo nacional moçambicano, distanciando-se, desse modo, a uma simples aplicação direta ou dogmática soviética - em que o exemplo da Tanzânia de Nyerere parece ter sido importante. Junto a esta referência, deve-se sempre levar em conta o primado da adaptação às exigências moçambicanas ou mesmo a nacionalização do marxismo que, como se sabe, foi levada adiante pela via chinesa. Não está em causa, aqui, medir o grau destas influências nem tampouco a hierarquização das mesmas. Quer-se, apenas, apontar o grau de complexidade existente entre a construção do ideário revolucionário em Moçambique e como ele será desenvolvido nos primeiros anos do Pós-Independência.

\section{A construção do "Homem Novo" em Moçambique}

Apesar das variadas influências teórico-práticas, em 1977, durante seu IV Congresso, o partido Frelimo adota oficialmente a estruturação política "marxista-leninista" como linha-mestra para a organização de seu projeto de construção nacional (NEWITT, 2002; THOMAZ, 2008; MALOA, 2011). É de se levar em conta que, no mesmo ano, havia estourado a guerra civil no país. A análise ideológica e geopolítica da África Austral naquele contexto mostra como a guerra civil moçambicana estaria vinculada aos embates existentes entre o "socialismo africano", por um lado, e o modelo racista de apartheid da Rodésia, de Ian Smith, e da África do Sul, de Peter Botha (SILVA, 2013). Naquele contexto, vale lembrar, Moçambique pode ser considerado como uma "ilha" lusófona em meio a um "oceano" de países anglófonos (África do Sul, Zimbábue, Zâmbia, Malaui, Tanzânia). O que pode ter sido relevante para a adoção do idioma português como língua oficial do novo Estado-Nação. Explica-se. Afinal, a adoção desse idioma marcaria a diferença tanto horizontalmente, diante dos demais Estados nacionais independentes, como

Anos 90, Porto Alegre, v. 21, n. 40, p. 131-161, dez. 2014 
também marcaria verticalmente no tempo histórico, posto marcar uma óbvia distinção relativamente às chamadas línguas e culturas tradicionais. Estes elementos não devem ser deixados de lado quando se olha para o recrudescimento do projeto de construção identitária em Moçambique.

É fato, entretanto, que, mesmo durante o período de transição (entre o acordo de Lusaka, em 7 de setembro de 1974, até a Independência, em 25 de junho de 1975), a Frelimo teria posto em marcha o que foi chamado de Operação Limpeza. Esta política apresenta a ação de grupos militares vinculados ao governo realizando o bloqueio de ruas e becos do centro de Lourenço Marques, fechando bares e cabarés. Seu objetivo era prender "marginais" e agitadores da oposição. Parte destes presos foi levada para "campos de reeducação" popular. Conforme Thomaz, a política manifestava "o caráter moral da revolução em curso" (2008, p. 179), representando o caráter compulsório do enquadramento social vinculado ao projeto socialista com o desígnio maior de superar os "vícios" sociais atribuídos ao passado a ser riscado (ora vinculados ao racismo e ao colonialismo, ora aos valores burgueses e ao capitalismo, e mesmo às fidelidades étnicas, regionais ou tradicionais). Trata-se, assim, do momento-chave na forja de criação do "Homem Novo" em Moçambique.

A política de construção de um "novo" cidadão moçambicano não foi peculiaridade do período de transição, vindo a recrudescer nos anos seguintes. Destaca-se a forte experiência da chamada Operação Produção. Organizada a partir de 1981, tratava-se da organização do projeto de reeducação popular em grandes campos de cultivo rural - as machambas - localizados no interior do país, sendo a maioria no norte do país, nas regiões do Cabo Delgado e Nampula. Conforme Omar Ribeiro Thomaz (2008), em 1982, havia cerca de 1.352 machambas, quase todas funcionando como um verdadeiro laboratório de reconversão política para onde eram enviados quaisquer indivíduos que simbolizassem valores ou práticas políticas ou moralmente condenáveis. Na prática, tratava-se de grandes acampamentos para onde eram enviados "marginais", "suspeitos" ou inimigos políticos (como Uria Simango). Nas machambas, todos teriam que trabalhar na lavoura durante o dia, construir suas palhoças e, ao final da jornada, assistir a cursos de marxismo-leninismo. Conforme o referido autor, 
durante a vigência da Operação Produção, as forças de segurança saíam às ruas das principais cidades do país exigindo que as pessoas mostrassem carteiras de trabalho, no caso de homens, ou comprovantes de casamento, no caso das mulheres.

Em discurso realizado em 1981, Samora Machel assim pronunciava-se sobre as machambas comunais:

Política e militarmente foi forjada a unidade, a partir de um pensamento consciência patriótica de classe. Entramos em Nashingwea como Macondes, Macuas, Niajas, Manicas, Shanganas, Ajauas, Rongas, Senas; saímos Moçambicanos. Entramos como negros, brancos, mistos, indianos; saímos moçambicanos. Quando chegamos, trazemos nossos vícios e defeitos, egoísmo, liberalismo, elitismo. Nós destruímos estes valores negativos e reacionários. Nós aprendemos a incorporar os hábitos e os comportamentos de um militante da Frelimo. Quando entramos, temos uma visão limitada, pois conhecemos apenas nossa região. Lá, aprendemos a escala do nosso país e os valores revolucionários (MACHEL, 1981 apud TOMAZ, 2008, p. 181).

Fica clara a influência da experiência da formação da própria FRELIMO, sobretudo no que remete à Nashingwea, campo de treinamento na Tanzânia antes da Independência. No mesmo sentido, pode-se articulá-lo aos acampamentos rurais levados a cabo na Tanzânia, que simbolizavam a existência do "socialismo tradicional", a Ujamaa do projeto de Julius Nyerere (MALOA, 2011). Este ponto é confirmado com o depoimento de um ex-combatente da FRELIMO que esteve no campo de educação na Tanzânia. Em entrevista contida na coletânea de memórias dos combatentes, organizada por Raimundo Pachinuapa, Domingos Fondo revela que

[...] antes de entrar na luta, recebi treinos ministrados por chineses, incluindo aulas políticas, nas quais eles preparavam os guerrilheiros para uma guerra prolongada. Encontrei pessoas oriundas de quase todos os pontos do País, expressando-se 
nas mais variadas línguas. Para nos comunicarmos nos treinos, às vezes eram necessários vários intérpretes. Os chineses falavam na sua língua e as palavras eram interpretadas para o português, e daí para as línguas nacionais (FONDO apud PACHINUAPA, 2011, p. 17).

O programa da Frelimo passava inegavelmente pela luta contra as fidelidades do passado, sejam as do colonialismo, sejam as do tradicionalismo. Assim, a experiência das aldeias comunais de reeducação apontam para o uso "científico" dos acampamentos no sentido da construção de um cidadão alinhado ao Estado-Frelimo. Isto, paradoxalmente, abre espaço para que se perceba a ressignificação de algumas práticas e tipos sociais muito caros ao período colonial português, agora já com nova roupagem pós-colonial socialista.

Refletindo sobre a questão do assimilado e a forma como o Estado Socialista Pós-Colonial teria agido com este "sobrevivente" do passado, Omar Ribeiro Thomaz faz uma interessante observação sobre os anos imediatamente posteriores à Independência. Diz o autor que o assimilado

[...] passou a ocupar um lugar decisivo no funcionamento do aparelho de um Estado que não apenas adotou o português como língua oficial, mas, no interior do projeto marxista-leninista, apropriou-se com um propósito revolucionário de um conjunto de atributos anteriormente associados à civilização" (2005, p. 257).

Há, portanto, que recusar algumas simplificações ingênuas que postulam a coincidência e mesmo a continuidade entre a construção identitária anterior ao processo de independência nacional e o momento posterior. Mais do que uma recuperação identitária prévia, tratava-se da construção de algo novo e em direção oposta ao passado. Este projeto - e até para fazer o contraste ao tradicional (entendido como supersticioso e "velho") - foram utilizadas compreensões de ordem "científica" no que tange aos objetivos a serem alcançados. O lugar do assimilado neste novo projeto era, desse modo, estratégico. 
O trabalho de António Cipriano Parafino Gonçalves, ao analisar as contradições existentes na concepção de politecnia em Moçambique, deixa algumas importantes considerações sobre o uso do conhecimento, por parte das estruturas do Estado-Frelimo, com o intuito de transformação da sociedade no desenvolvimento da proposta de aliar a teoria com a prática revolucionária. $\mathrm{O}$ autor analisa a documentação vinculada ao Sistema Nacional de Educação em Moçambique. Para os objetivos deste artigo, basta recuperar excertos da proposta apresentada pelo Ministério de Educação e Cultura em 1981 e aprovado pela Assembleia da República, vindo a ser promulgada em 1983. Em linhas gerais, pode-se dizer que o objetivo central atribuído ao projeto educacional moçambicano naquele contexto era o de formar o Homem Novo Revolucionário, ou seja, "[...] um homem livre do obscurantismo, da superstição e da mentalidade burguesa e colonial, um homem que assume os valores da sociedade socialista" (MOÇAMBIQUE, 1985, p. 113 apud GONÇALVES, 2007, p. 604). Não parece haver forte dessemelhança alguma entre este documento de implementação de um projeto de educação nacional e as linhas de pensamento divulgadas ainda no período final da luta pela libertação. Fica claro o objetivo de usar as estruturas estatais para a construção de um novo ideal societário. A moçambicanidade é, obviamente, também fruto deste processo.

Gabriel Mithá Ribeiro (2007), por sua vez, apoiado em expressivo número de entrevistas realizadas na cidade de Tete em 2004, chama atenção para um elemento complicador na forma como costumeiramente são percebidos os momentos de transição política. $\mathrm{O}$ autor descreve a presença, na memória dos sobreviventes dos campos de reeducação popular, de uma compreensão que enxerga ter havido a transferência do caráter obrigatório e violento dos aldeamentos portugueses coloniais (realizados na década de 1960) e as machambas comunais. Dentre essas memórias coletadas, destaca-se a permanência do uso do chibalo (chicote) como instrumento utilizado para realização de trabalhos forçados. O encarte Público Magażine, publicado em 1995, a pretexto dos vinte anos da revolução, apresenta dados comprobatórios disso (PÚBLICO, 25/06/1995). 
Esta informação é também confirmada pelo trabalho de Omar Ribeiro Thomaz, com uma ressalva: se no período colonial a identidade de escravo estava vinculada a um proprietário individual, no período pós-independência, a percepção era de que os integrantes dos campos de reeducação popular eram "escravos sem dono" (THOMAZ, 2008).

Fato é, contudo, que as práticas repressoras e a ação policialesca de funcionários estatais no sentido de controlar a sociedade moçambicana durante a I República será um dos elementos contribuintes para resistências e para a negatividade da memória vinculada aos "tempos de Samora". Este ponto abre outra questão pouco abordada quando se analisa genericamente os "nacionalismos africanos". O trabalho de Fernando Bessa Ribeiro (2005) aponta para o caráter estratégico da recuperação da história e da construção de mitologias nacionalistas. Sua análise destaca a construção política do mito Ngungunhane (o último soberano do Império de Gaza, no final do século XIX), bem como sua vinculação à memória de Eduardo Chivambo Mondlane (primeiro líder da FRELIMO, morto em 1969).

Vale dizer que, em cada etapa, naturalmente, foram ressignificados os termos nos quais a própria construção identitária foi pensada ou proposta, independentemente da escala referida: regional, étnica ou nacional. O que é natural, visto serem as condições contextuais e o ideário mobilizado nelas cambiante. É muito difícil, a não ser por arroubos românticos e/ou historicistas, estabelecer indelevelmente um fio condutor único ligando gerações, ideias, projetos políticos e contextos distintos.

Trata-se de chamar atenção para a existência também na África - e porque haveria de ser diferente? - da importância de o historiador ter consciência sobre o caráter político vinculado à construção dos heróis nacionais - tão prenhes de "tradições inventadas", processo muitíssimo atrelado a tentativas de politização de memórias históricas $^{15}$. Contudo, e por mais relevantes que sejam os meandros de problema, a análise deste complexo jogo de produção política da história vai além dos objetivos deste artigo. 


\section{Considerações finais: a complexidade do projeto nacional moçambicano}

Do que anteriormente foi exposto, deve-se guardar a necessária dose de precaução contra quaisquer tentações generalistas sobre as identidades e os nacionalismos na África. A simples exposição de alguns dados vinculados à história contemporânea de Moçambique deixa muito clara a complexidade de algumas questões: a descolagem do modelo europeu de construção nacional; o não alinhamento simples do ponto de vista ideológico no âmbito das variadas influências de cariz genericamente marxista; a importância de tratar das peculiaridades de cada projeto de construção nacional, tendo especial atenção para a historicidade das proposições políticas (dentro, por exemplo, das modificações no interior da FRELIMO); a valia de analisar a vasta zona problemática existente entre o lastro de continuidades mantidas - seja por resiliência, seja por deliberada conveniência - entre um antes e um depois marcado pela data factual da Independência Nacional.

O fato é que a luta anticolonial não termina com a proclamação de independência de Moçambique, em 25 de junho de 1975. Após a transição política oficial, há todo um longo e intenso processo de reconversão de expectativas no qual a construção de novas práticas sociais deveria justamente refletir a ascensão da almejada soberania. Portanto, além de instaurar uma ruptura política, havia de deixá-la muito evidente. Este processo não é nem imediato nem é possível de ser completado totalmente. Afinal, por vezes, o desígnio de marcar a ruptura pode - paradoxalmente - mostrar a adoção de práticas próximas daquilo mesmo que se quiser distanciar. E no caso moçambicano pós-Independência isto talvez tenha se manifestado na adoção de métodos científicos como meios necessários para criação da novidade e da ruptura cultural, assim como na adoção de práticas repressivas por parte dos agentes estatais no sentido de coibir quaisquer manifestações dissonantes ao projeto político perseguido. Relativamente ao caso específico moçambicano, estudos recentes em história oral e antropologia têm revelado a existência de memórias políticas, em setores da sociedade moçambicana, que 
postulam certa continuidade do aparato repressivo entre o Estado Colonial e o Estado Socialista Pós-Independência. A "verdadeira independência" teria, conforme alguns relatos, chegado apenas no período da II República, da paz e do multipartidarismo (RIBEIRO, 2007; TOMAZ, 2008). Chamar atenção para a complexidade da construção da identidade nacional em Moçambique significa fazer um constante esforço por renunciar as simplificações e os binarismos políticos. Significa também renunciar às compreensões simplistas acerca do tempo histórico e de como ele é assimilado em memórias sociais. Vale deixar claro que a reflexão sobre a complexidade destas questões anteriormente apontadas - que se aglutinam no problema teórico da ruptura histórica - em nada desabona a relevância política e as importantes conquistas do período posterior à Independência de Moçambique.

Parece ter ficado claro que o caso da construção da nação em Moçambique repousa sobre múltiplas camadas identitárias em que se misturam presenças culturais de diferentes períodos com lógicas de ruptura política e de construção de uma "nova" sociedade. A metáfora do palimpsesto, usada por Maylin Newitt quando abordava as camadas culturais moçambicanas no período pré-colonial, pode também ser utilizada como referência para se pensar a construção da "moçambicanidade" durante o Estado Pós-Colonial Socialista. Para o historiador que se interessar pela identidade nacional no Moçambique contemporâneo, sugere-se que se lembre do palimpsesto de Newitt, articulando-o ao uso das temporalidades da história e do caráter político de suas narrativas. Creio que isso pode ajudar para que não se caia - novamente - nas resilientes e ideológicas simplificações quando são abordadas as identidades nacionais e os nacionalismos na África, em geral, e em Moçambique, de modo particular. 


\section{THE CONSTRUCTION OF MOZAMBICAN POST-INDEPEN- DENCE NATIONAL IDENTITY: THIS COMPLEXITY AND SOME RESERCH PROBLEMS}

Abstract: This article addresses the complexity of the national building process in Mozambique post-Independence (1975). Firstly, it discusses some theoretical references for the African identities in general and the African nationalism in particular. It claims the abdication of generalist interpretations and proposes to approach the Mozambican case. It analyzes the political and ideological project of FRELIMO (Liberation Front of Mozambique) giving attention to how the national building is understood. It highlights in this case, the way of the traditional identities, racism and colonial heritages were opposed to the creation of New Man project in the country by a particular reading of Mozambicanity.

Keywords: Mozambican history. National identity. Nation and nationalism. African socialisms. New man building.

\section{Notas}

${ }^{1}$ Utilizo aqui o termo moçambicanidade para expressar a condição da nacionalidade em Moçambique. O conceito vincula-se ao processo de partilha de signos e valores de identidade coletiva sediados em escala nacional, por um lado, e legitimados jurídico-politicamente pelo Estado, por outro. É importante ter presente a relevância deste tipo de identidade social, sobretudo no contexto posterior à Segunda Guerra e à fundação das ONU. Como linha-mestra de um realinhamento geopolítico internacional, aceita-se e advoga-se a existência de um Estado para cada Nação, o que remete, também, a um importante processo de definição interna e externa dos membros de cada Estado-Nação. Não é este o lugar apropriado para desenvolver todos os contornos teóricos desta questão. Basta dizer que este postulado foi um importante elemento no processo de luta anticolonial e de independência na Ásia e na África. Tendo como foco o caso moçambicano em particular, basta chamar atenção para que a importância desta definição conceitual não ficasse desassistida na proclamação da independência de Moçambique, nem tampouco nos seus primeiros documentos oficiais. Para mais informações sobre este último ponto, consultar Muiuane (2009).

${ }^{2}$ Embora tenha presente o papel relevante das narrativas literárias no processo de construção da moçambicanidade - lembre-se de Luis Bernardo Honwana, José Craveirinha, Mia Couto, Paulina Chiziane, entre muitos outros - não me aterei, neste texto, sobre este elemento da questão identitária. 
${ }^{3}$ A distinção entre FRELIMO e Frelimo busca chamar atenção para a diferença entre uma frente ampla de movimentos políticos reunidos no combate anticolonial, no período pré-Independência, e a transformação desta em partido político único e com uma orientação ideológica definida. No primeiro caso, trata-se de uma sigla e por isso é escrito em letras maiúsculas; no segundo, trata-se de um nome de agremiação política. Esta distinção é importante e busca não confundir nem tampouco alinhavar de maneira simplista e historicista os contextos anterior e posterior à Independência.

${ }^{4}$ Veja-se, por exemplo, Delannoi e Taguieff (1992); Özkirimli (2000) e Balakrishnan (2000).

${ }^{5}$ Refiro-me à geração intelectual que, nas universidades europeias e americanas, especialmente no contexto do pós-II Guerra Mundial, construiu um "campo" acadêmico de debate sobre as nações e os nacionalismos. Obviamente não refiro, assim, aos textos seminais de autores como Ernest Renan, Johann G. Fichte entre outros, embora a África, nalguns deles, também tenha povoado suas páginas.

${ }^{6}$ Veja-se, a este título, o debate entre as obras de Nairn (1977), Hobsbawm (2006; 2008), Hasting (2000) e Smith (1997; 2009).

${ }^{7}$ Sabe-se, obviamente, do postulado teórico-político de Amilcar Cabral ou mesmo de Julius Nyerere que, de maneiras distintas, buscavam uma recuperação ou uma reafricanização da própria África. Vale dizer que um projeto tal só é possível a partir da sensação de perda da própria tradição a ser recuperada. Sobre esta questão, ver, entre outros, HOBSBAWM e RANGER (2008) e ZELEZA (2006). ${ }^{8}$ Para uma caracterização histórico-social de Moçambique no início do século XX, consultar ZAMPARONI, 1998.

${ }^{9}$ Craveirinha foi preso pela PIDE, a política-política portuguesa, como membro da FRELIMO, ficando recluso entre 1965 e 1969. No período pós-colonial, foi o primeiro presidente da Associação dos Escritores Moçambicanos, em 1982.

${ }^{10}$ A RENAMO, Resistência Nacional Moçambicana, foi organizada enquanto um movimento de oposição e resistência às políticas do governo da Frelimo no período Pos-Independência. Sobre a RENAMO, naquele contexto, há inúmeras acusações de violência e ataques às populações rurais, tribalismo, apoio da África do Sul, de Peter Botha, etc. Não é este o lugar para discutir sua formação e suas principais características. Para maiores informações, consulte-se VIEIRA (2013). ${ }^{11}$ De resto, apenas uma leitura ideologizada ao extremo deixaria de considerar pontos positivos do período da construção moçambicana (em que são relevantes o aumento das infraestruturas de educação, saúde pública e promoção da igualdade de gênero, por exemplo), assim como o lado mais negativo vinculado a este mesmo processo de "costura política" da nação (falta de democracia, perseguições políticas, repressão do aparelho burocrático estatal). Frente a estes 


\section{A construção da identidade nacional moçambicana...}

elementos todos, seguem muitos pontos por serem melhor compreendidos e analisados. Dentre alguns deles, pode-se elencar: a permanência da violência estatal no período anterior e posterior ao 25 de junho de 1975 (THOMAZ, 2008); a desestruturação burocrática e econômica na mesma transição; o desequilíbrio da relação entre cidade e campo, entre o rural e o urbano; o déficit democrático e o caráter ditatorial do Estado etc. Todas estas perguntas (e tantas outras mais) estão vinculadas aos intrincados períodos de transição política e demandam maior número de pesquisas.

${ }^{12}$ A designação de I República é costumeiramente usada para diferenciar-se da II República, inaugurada em 1889, sob o governo de Joaquim Chissano. É o período marcado pela adoção do multipartidarismo e pela abertura do país ao capitalismo de mercado.

13 "Do Rovuma ao Maputo": bordão de referência aos rios limítrofes a norte e a sul, simbolizando a unidade nacional. Remete à célebre marcha encabeçada por Samora Machel, em 24 de maio de 1975, em Mueda, na província de Cabo Delgado. ${ }^{14}$ Faço aqui referência à obra de Anne-Marie THIÈSSE. Dentre seus livros, destaco Ils apprenaient la France (1997); La creation des identités nationales (1999) e o artigo Ficções criadoras: as identidades nacionais, Anos 90, Porto Alegre, n.15, $2001 / 2002$.

${ }^{15}$ Veja-se, por exemplo, o último capítulo da obra de Patrick Geary (2008).

\section{Referências}

APPIAH, K. A. Na Casa de Meu Pai. A Africa na filosofia da cultura. Rio de Janeiro: Contraponto, 1997.

BALAKRISHNAN, G. (Org.). Um mapa da questão nacional. Rio de Janeiro: Contraponto, 2000.

CHABAL, P. A History of Postcolonial Lusophone Africa. Indiana: Indiana University Press, 2002.

Imagined Modernities: community, nation and state in postocolonial Africa. In: TORGAL, L.R.; PIMENTA, F.T.; SOUSA, J.S. Comunidades Imaginadas. Nação e nacionalismos em Africa. Coimbra: Imprensa da Univ. de Coimbra/ CEIS20, 2008. p. 41-48.

CRAVEIRINHA, J. O Folclore moçambicano e as suas tendências. Maputo: Alcance Editores, 2009. 
DELANNOI, G.; TAGUIEFF, P-. Théories du nationalisme. Nation, nationalité, ethnicité. Paris: Kimé, 1992.

ENDERS, A. História da Africa Lusófona. Mira-Sintra: mem Martins, 1997.

FELICIANO, J. F. Prefácio. In: JUNOD, H. Usos e Costumes dos Bantos. Tomo I: Vida Social. Maputo: Arquivo Histórico de Moçambique, 1996.

FRELIMO. Estatutos e Programas da Frente de Libertação de Moçambique (1968). In: MUIUANE, A. P. Datas e Documentos da História da FRELIMO. 3. ed. revista, melhorada e ampliada. Maputo: Imprensa Nacional de Moçambique, 2009. GEARY, P. O Mito das Nações. A invenção do nacionalismo. Lisboa: Gradiva, 2008. GILROY, P. O Atlântico negro. São Paulo: Editora 34; Rio de Janeiro: Universidade Cândido Mendes, 2008.

GONÇALVES, A. C. G. A concepşão de politecnia em Moçambique: contradições de um discurso socialista (1983-1992). Educação e Pesquisa. São Paulo, v. 33, n. 3, p. 601-619, set./dez. 2007. Disponível em: http://www.revistas.usp.br/ep/ article/view/28069. Acesso em: 20. mar. 2014.

HASTINGS, A. La construcción de las nacionalidades. Madrid: Cambridge univ. Press, 2000.

HOBSBAWM, E. Nações e Nacionalismos desde 1780: programa, mito e realidade. Rio de Janeiro: Paz e Terra, 1990.

HOBSBAWM, E.; RANGER, T. A invenção das Tradições. Rio de Janeiro: Paz e Terra, 2008.

KOHN, H.; SOKOLSKY. El nacionalismo africano em el siglo XX. Buenos Aires: Paidós, 1968.

JUNOD, H. Usos e Costumes dos Bantos. Tomo I: Vida Social. Maputo: Arquivo Histórico de Moçambique, 1996.

MACAMO, E. A Nação Moçambicana como comunidade de destino. Lusotopie, p. 355-364, 1996. Disponível em: http:/ / www.lusotopie.sciencespobordeaux.fr/ macamo96.pdf. Acesso em: 20 fev. 2014.

MACHEL, S. M. Discurso de Estado do Camarada Presidente da FRELIMO Samora Moisés Machel na tomada de posse de Presidente da Republica Popular de Moçambique. In: MUIUANE, A. P. Datas e Documentos da História da FRELIMO. 3. ed. revista, melhorada e ampliada. Maputo: Imprensa Nacional de Moçambique, 2009. 


\section{A construção da identidade nacional moçambicana...}

MALOA, J. M. O lugar do marxismo em Moçambique: 1975-1994. Revista Espaço Acadêmico, n.122, julho de 2011. Disponível em: http:/ /www.periodicos.uem.br/ ojs/index.php/EspacoAcademico/issue/view/510. Acesso em: 10 mar. 2014.

MARTIN, G. African Political Thought. New York: Palgrave Macmillan, 2012.

MBOKOLO, E. História da África Negra. Salvador: EDUFBA; São Paulo: Casa das Áfricas, 2011.

MONDLANE, E. C. tribos e Grupos étnicos Moçambicanos (seu significado na Luta de Libertação Nacional (1967): In: MUIUANE, A. P. Datas e Documentos da História da FRELIMO. 3. ed. revista, melhorada e ampliada. Maputo: Imprensa Nacional de Moçambique, 2009.

MUIUANE, A. P. Datas e Documentos da História da FRELIMO. 3. ed. revista, melhorada e ampliada. Maputo: Imprensa Nacional de Moçambique, 2009.

MUNDIMBE, V. Y. A Invenção da África. Gnose, Filosofia e a Ordem do Conhecimento. Lisboa: Pedago; Luanda: Edições Mulemba, 2013.

NAIRN, T. The Break-Up of Britain. Crisis and neo-nationalism. Edinburg: Common Ground, [1977], 2003.

NEWIT'T, M. Mozambique. In: CHABAL, Patrick. A History of Postcolonial Lusophone Africa. Indiana: Indiana University Press, 2002.

OLARTUNJI, O. A política e o nacionalismo africanos, 1919-1935. In: História Geral da África. vol. VIII. Editado por Ali Mazrui e Christophe Wondji, Brasília: UNESCO, 2010.

ÖZKIRIMLI, U. Theories of nationalism: a critical introduction. New York: St. Martin Press, 2000.

PACHINUAPA, R. (Coord.). Memórias da Revolução 1962-1974. Colectânea de entrevistas de combatentes da Luta de Libertação Nacional. vol. I. Editado por Carlos Jorge Siliya. Maputo: Centro de Pesquisa da História da Luta de Libertação Nacional, 2011.

PÚBLICO MAGAZINE. Os campos da vergonha, n. 277, 25/06/1995.

RIBEIRO, F. B. A Invenção dos Heróis: nação, história e discursos de identidade em Moçambique. Etnográfica, vol.IX, n.2, p.257-275, 2005. Disponível em http:/ / www.scielo.oces.mctes.pt $/$ scielo.php? script $=$ sci_nlinks\&ref $=000144 \&$ pid $=$ S0003-2573200900040000800002\&lng=pt. Acesso em: 15 dez. 2013.

RIBEIRO, G. M. Chissano contra Machel e o Colono: representações sociais do estado em Moçambique. Cadernos de Estudos Africanos, n.13/14, 2007. Disponível em: https://repositorio.iscte-iul.pt/handle/10071/2673. Acesso em: 15 mar. 2014.

Anos 90, Porto Alegre, v. 21, n. 40, p. 131-161, dez. 2014 
SANCHES, M. R. Malhas que os impérios tecem: textos anticoloniais, contextos pós-coloniais. Lisboa: Edições 70, 2011.

SAUL, J. Rethinking the FRELIMO State. Socialist Register, v.29, 1993. Disponível em: http://web.iaincirebon.ac.id/ebook/moon/Decentralization/Braathen Mosambik.pdf. Acesso em: 10 mar. 2014.

SILVA, S. V. da. Politica e poder na Africa Austral (1974-1989). Lisboa: Escolar Editora, 2013.

SMITH, A. The etno-symbolism and nationalism. New York: Routlegde, 2009. . Identidade Nacional. Lisboa: Gradiva, 1997.

THIÈSSE, A-M. Ficções criadoras: as identidades nacionais. Anos 90. Porto Alegre, n. 15, 2001/2002.

. Ils apprenaient la France: L'exaltation des region dans le discours patriotique. Paris: Maison des Sciences de l'homme, 1997.

La création des identités nationales. Paris: Seuil, 1999.

THOMAZ, O. R. “'Escravos sem dono': a experiência social dos campos de trabalho em Moçambique no período socialista". Revista de Antropologia. São Paulo, USP, v.51, n.1, 2008. Disponível em: http://www.revistas.usp.br/ra/article/ viewFile/27305/29077. Acesso em: 5 mar. 2014.

. Raça, nação e status: história de guerra e 'relações raciais' em Moçambique. Revista da USP, São Paulo, n.68, p. 252-268, dez./ fev. 2005-2006. Disponível em: http://www.usp.br/revistausp/68/19-omar-ribeiro.pdf. Acesso em: 10 mar. 2014.

VIEIRA, S. Participei, por isso testemunho. Maputo: Ndira, 2011.

ZAMPARONI, V. Ente 'Narros e Mulngos': colonialismo e paisagem social em Lourenço Marques 1890-1940. Doutorado em História Social. São Paulo: USP, 1998.

ZELEZA, P. T. The invention of African Identities and Languages. The Discoursive and Developmental Implications. In: Selected Proceedings of the 36th Conference on African Linguistics. Edited by OlaobaAransanyinand Michael Pemberton. Somerville, MA: Cascadilla Proceding Project, 2006. Disponível em: http://www.lingref. com/cpp/acal/36/paper1402.pdf. Acesso em: dez. 2013.

Recebido em: 02/04/2014

Aprovado em: 20/08/2014 